\title{
A STUDY OF NEGATIVE PRESSURE WOUND THERAPY: VACUUM ASSISTED CLOSURE IN CHRONIC NON-HEALING ULCERS
}

\author{
Dhamotharan Senraman Rajan ${ }^{1}$, Jaideep Pradeep² \\ 1 Professor and Unit Chief, Department of General Surgery, Madurai Medical College, Madurai. \\ ${ }^{2}$ Post Graduate Student, Department of General Surgery, Madurai Medical College, Madurai.
}

\section{ABSTRACT}

\section{BACKGROUND}

This study evaluates the advantage of Negative Pressure Wound Therapy-Vacuum Assisted Closure over Conventional Dressing in the management of chronic non-healing ulcers.

\section{METHODS}

From June 2014 to June 2015, 50 patients were selected (25 cases and 25 controls). After wound debridement, VAC dressing is applied. Pre VAC and post VAC culture and sensitivity is taken. Dressing is given for 72 hours and intermittent suction is given for 10 mins. in an hour, daily for 12 hours with negative pressure ranging from 100 to $125 \mathrm{mmHg}$. Rest of the time drain of the VAC dressing is connected to the Romovac suction drain. Doppler study to assess the vascularity of the limb before the procedure and X-ray is taken to rule out osteomyelitis. Control group patients are given conventional dressings.

\section{RESULTS}

The gender, age and ulcer distributions were almost equal in the case and control groups and were found to be statistically insignificant. Duration of hospital stay in days was found to be statistically significant between groups. Majority (52\%) of cases left hospital within 3 weeks' time, while a major chunk (88\%) of control population stayed more than 3 weeks. VAC dressing shows better results in patients with normal Doppler study. VAC dressing have better results in patients with $48 \%$ undergoing split skin grafting and less rate (8\%) of amputation as against none undergoing split skin grafting and $24 \%$ needing amputation in the control group. Patients with sterile pre-VAC culture were not turning unsterile after VAC, but $90 \%$ unsterile turns sterile after VAC.

\section{CONCLUSION}

NPWT is a novel technique for managing an open wound by submitting the wound either to intermittent or continuous subatmospheric pressure. Here, we did a study to study the advantage of vacuum assisted closure over conventional dressing in the management of chronic non-healing ulcers and concluded that VAC decreases hospital stay, improves pus culture sterility, has better result in patient with normal Doppler, improves outcome by decreasing the number of amputations and increases the number of patients undergoing split skin grafting.

\section{KEYWORDS}

Vacuum Assisted Closure, Negative Pressure Wound Therapy, Ulcer.

HOW TO CITE THIS ARTICLE: Rajan DS, Pradeep J. A study of negative pressure wound therapy: vacuum assisted closure in chronic non-healing ulcers. J. Evolution Med. Dent. Sci. 2016;5(44):2754-2757, DOI: 10.14260/jemds/2016/643

\section{INTRODUCTION}

Amongst the most common causes for admission in general surgical ward is chronic non-healing ulcer of which diabetes is the most common aetiology. In most of the cases, hospital stay of many weeks is required for management of the above. In many cases they ultimately go in for amputation and at times even death of the patient. In all sense, patients turn to be a burden for society and family. The Vacuum Assisted Closure (VAC) therapy (Also known as negative pressure wound therapy) since its introduction in 1990's has revolutionized the modern wound care.

The practice of exposing a wound to sub-atmospheric pressure for an extended period to promote debridement and

Financial or Other, Competing Interest: None.

Submission 15-03-2016, Peer Review 14-04-2016,

Acceptance 20-04-2016, Published 02-06-2016.

Corresponding Author:

Dr. S. R. Dhamotharan,

Resd: 403/3,

Indian Bank Colony,

Narayanapuram,

Madurai-14.

E-mail: sr_dhamotharan@yahoo.com

DOI: $10.14260 /$ jemds/2016/643 healing was first described by Fleischmann et al in $1993 .{ }^{1}$ following the successful use of this technique in 15 patients with open fractures. . $3,3^{2,4}$

It has been successfully used in the wounds caused by burns, infections, exposed bone or artificial implants and dehiscence.5,6,7 Negative pressure therapy facilitates the healing by improving the rate of angiogenesis, endothelial proliferation, the integrity of the capillary membrane, capillary blood flow, capillary calibre and by decreasing interstitial oedema and bacterial burden within the wound. It has proved its efficacy for wound dressing, faster wound healing and shorter hospital stay.

The purpose of this type of wound management is to decrease wound healing time and to facilitate wound care in situations that otherwise might be considered difficult or nonhealing. This article reports our experience with VAC and its advantages over conventional dressing.

\section{MATERIALS AND METHODOLOGY}

Between June 2014 to June 2015, 50 patients were selected (25 cases and 25 controls) randomly. Patients included in study are classified according to the grade of the ulcer (Wagner classification). All grades were included except grade 0 and 5 . Patients below 13 years and above 70 years were excluded 
from the study, so were patients with malignancy, active bleeding and those undergoing anticoagulant therapy, gangrenous foot, exposed blood vessels, untreated osteomyelitis, necrotic tissue in eschar and those with fistulas to organs or body cavities.

Patient selected for VAC therapy underwent wound debridement and haemostasis was achieved. Pre VAC culture and X-ray to rule out active osteomyelitis was taken. Doppler study to assess the vascularity of the limb before the procedure was also done. A piece of pre-sterilized foam of about $1 \mathrm{~cm}$ thickness is cut to the size of the wound and is placed on it. Then a perforated drainage tube (Romovac suction drain tube is used here) is put on it. Again a piece of foam is placed on the underlying foam and tube.

The whole foam with tube is covered with a sterile transparent dressing (Opsite). The tube is connected to a common suction apparatus with pressure gradient. Suction is applied with a negative pressure of 100 to $125 \mathrm{mmHg}$ for 10 mins hourly for 12 consecutive hours. Rest of the time, this drainage tube is connected to the Romovac suction apparatus. Dressing is changed after 72 hours and post VAC culture is taken. These cycles of dressings and vacuum are applied and statistical assessment was done using outcome variables. Control group patients were given conventional dressings.

Data were analysed using computer software, Statistical Package for Social Sciences (SPSS) version 10. Data are expressed in its comparison between controls and cases, chi square test was used as non-parametric test. For all statistical evaluations, a two-tailed probability of value, $<0.05$ was considered significant.

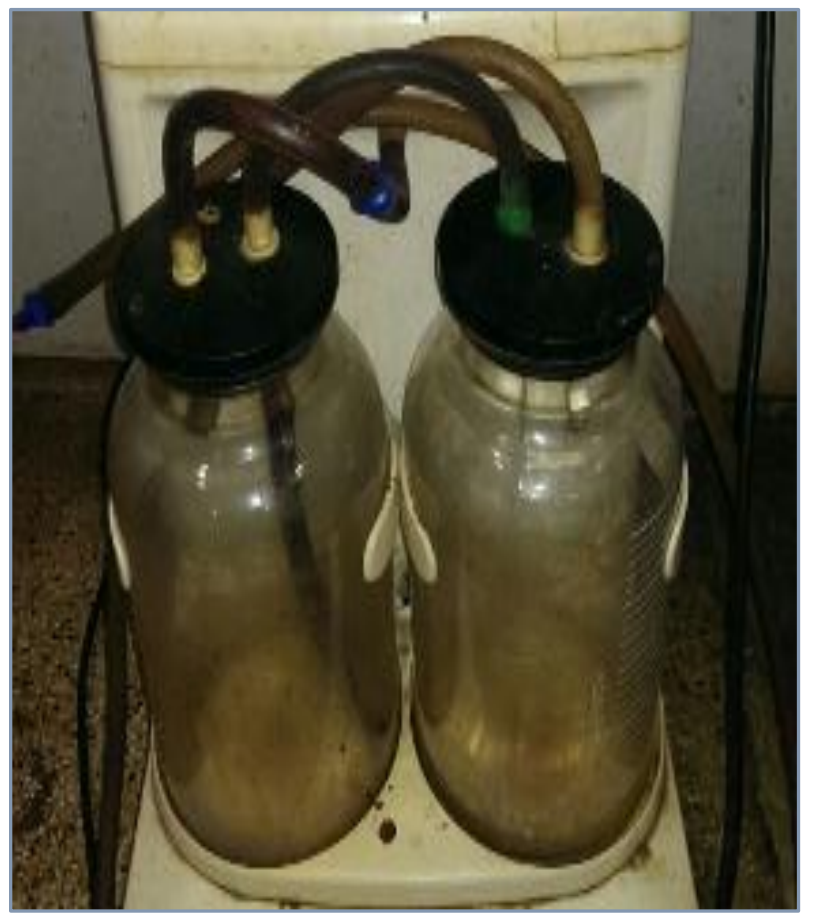

Fig. 1: Negative Suction Pump

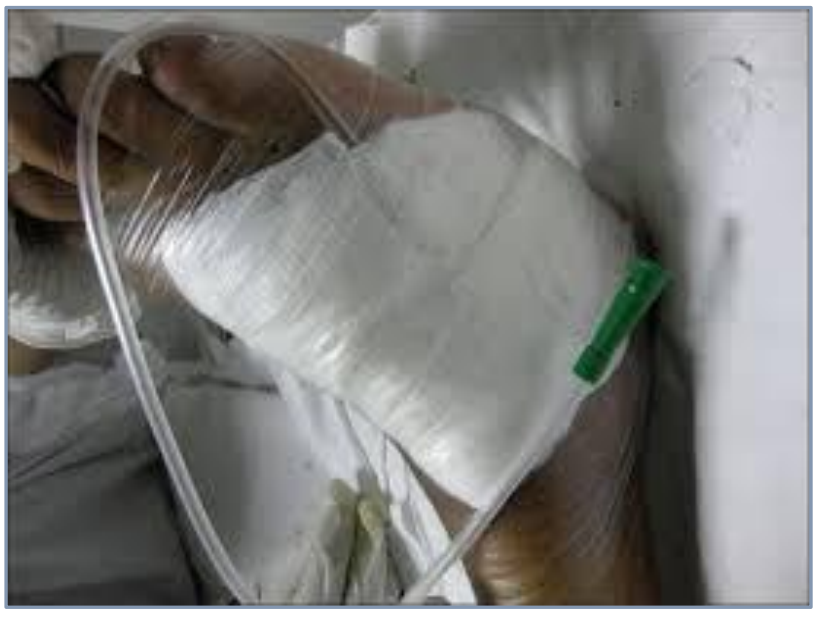

Fig. 2: Foam Dressing with Opsite

RESULTS

\begin{tabular}{|c|c|c|c|}
\hline Gender & Control & Cases & Total \\
\hline \multirow{2}{*}{ Male } & 18 & 14 & 32 \\
& $72.00 \%$ & $56.00 \%$ & $64.00 \%$ \\
\hline \multirow{2}{*}{ Female } & 7 & 11 & 18 \\
& $28.00 \%$ & $44.00 \%$ & $36.00 \%$ \\
\hline Total & $\mathbf{2 5}$ & $\mathbf{2 5}$ & $\mathbf{5 0}$ \\
\hline \multicolumn{3}{|c|}{ Table 1: Gender Distribution and Its } \\
Association with Group \\
\hline
\end{tabular}

Chi square: $1.389 ; \mathrm{p}>0.05$.

Gender difference between two groups was not found to be statistically significant.

\begin{tabular}{|c|c|c|c|}
\hline Age & Control & Cases & Total \\
\hline \multirow{2}{*}{$<40$ yrs. } & 1 & 2 & 3 \\
& $4.00 \%$ & $8.00 \%$ & $6.00 \%$ \\
\hline \multirow{2}{*}{$40-49$ yrs. } & 4 & 5 & 9 \\
& $16.00 \%$ & $20.00 \%$ & $18.00 \%$ \\
\hline \multirow{2}{*}{$50-59$ yrs. } & 11 & 8 & 19 \\
& $44.00 \%$ & $32.00 \%$ & $38.00 \%$ \\
\hline \multirow{2}{*}{$>60$ yrs. } & $960 \%$ & 10 & 19 \\
\hline \multicolumn{4}{|c|}{ Table 2: Age Distribution and Its Association with } \\
\hline
\end{tabular}

Chi square: $1.389 ; \mathrm{p}>0.05$.

Age distribution between two groups was not found to be statistically significant.

\begin{tabular}{|c|c|c|c|}
\hline $\begin{array}{l}\text { Duration of Hospital Stay } \\
\text { (Days) }\end{array}$ & Control & Cases & Total \\
\hline $7-14$ & $\begin{array}{c}1 \\
40.00 \\
\end{array}$ & $\begin{array}{c}6 \\
24.00 \\
\end{array}$ & $\begin{array}{c}7 \\
14.00 \\
\end{array}$ \\
\hline $14-21$ & $\begin{array}{c}2 \\
8.00 \\
\end{array}$ & $\begin{array}{c}7 \\
28.00 \\
\end{array}$ & $\begin{array}{c}9 \\
18.00 \\
\end{array}$ \\
\hline $21-28$ & $\begin{array}{c}10 \\
40.00 \\
\end{array}$ & $\begin{array}{c}6 \\
24.00 \\
\end{array}$ & $\begin{array}{c}16 \\
32.00 \\
\end{array}$ \\
\hline $28-35$ & $\begin{array}{c}6 \\
24.00 \\
\end{array}$ & $\begin{array}{c}5 \\
20.00 \\
\end{array}$ & $\begin{array}{c}11 \\
22.00 \\
\end{array}$ \\
\hline$>35$ & $\begin{array}{c}6 \\
24.00 \\
\end{array}$ & $\begin{array}{c}1 \\
4.00 \\
\end{array}$ & $\begin{array}{c}7 \\
14.00 \\
\end{array}$ \\
\hline Total & 25 & 25 & 50 \\
\hline $\begin{array}{r}\text { able 3: Duration of Hc } \\
\text { Associatio }\end{array}$ & $\begin{array}{l}\text { tal Sta } \\
\text { ith Gro }\end{array}$ & (ys) c & \\
\hline
\end{tabular}

Chi square: $11.012 ; \mathrm{p}<0.05$ 
Duration of hospital stay was found to be statistically significant. Majority (52\%) of cases left hospital within 3 weeks' time, while a major chunk (88\%) of control population stayed more than 3 weeks.

\begin{tabular}{|c|c|c|c|}
\hline Grade of Ulcer & Control & Cases & Total \\
\hline \multirow{2}{*}{ Grade 1} & 1 & 2 & 3 \\
& $4.00 \%$ & $8.00 \%$ & $6.00 \%$ \\
\hline \multirow{2}{*}{ Grade 2} & 10 & 11 & 21 \\
& $40.00 \%$ & $44.00 \%$ & $42.00 \%$ \\
\hline \multirow{2}{*}{ Grade 3} & 10 & 8 & 18 \\
& $40.00 \%$ & $32.00 \%$ & $36.00 \%$ \\
\hline \multirow{2}{*}{ Grade 4} & 4 & 4 & 8 \\
& $16.00 \%$ & $16.00 \%$ & $16.00 \%$ \\
\hline Total & $\mathbf{2 5}$ & $\mathbf{2 5}$ & $\mathbf{5 0}$ \\
\hline
\end{tabular}

Table 4: Grade of Ulcer and Its Association with Group

Chi square: $0.603 ; p>0.05$

Grade of ulcer distribution was almost equal in two groups and was not found to be statistically significant.

\begin{tabular}{|c|c|c|c|}
\hline Doppler Finding & Control & Cases & Total \\
\hline \multirow{2}{*}{ Normal } & 19 & 18 & 37 \\
\hline & 76.00 & 72.00 & 74.00 \\
\hline \multirow{2}{*}{ Vascular Impairment } & 6 & 7 & 13 \\
\hline & 24.00 & 28.00 & 26.00 \\
\hline Total & 25 & 25 & 50 \\
\hline \multicolumn{4}{|c|}{$\begin{array}{c}\text { Table 5: Doppler Findings and Its } \\
\text { Association with Group }\end{array}$} \\
\hline
\end{tabular}

Chi square: $0.104 ; \mathrm{p}>0.05$

Doppler findings in groups was not found to be statistically significant. But VAC dressing shows better results in patients with normal Doppler study.

\begin{tabular}{|c|c|c|c|}
\hline Outcome/Plan & Control & Cases & Total \\
\hline \multirow{2}{*}{ Discharge } & 19 & 11 & 30 \\
& 76.00 & 44.00 & 60.00 \\
\hline \multirow{2}{*}{ Split skin graft } & $\mathrm{Nil}$ & 12 & 12 \\
& 6 & 48.00 & 24.00 \\
\hline \multirow{2}{*}{ Amputation } & 24.00 & 8.00 & 8 \\
& $\mathbf{2 5}$ & $\mathbf{2 5}$ & $\mathbf{5 0}$ \\
\hline \multicolumn{3}{|c|}{ Total } & \multicolumn{3}{|c|}{ Table 6: Analysis of Cases and Control } \\
Groups in Outcome/Plan \\
\hline
\end{tabular}

Chi square: $16.133 ; \mathrm{p}<0.001$.

Chi square test shows study is significant as $\mathrm{p}$ value is less than 0.001 . So VAC dressing have better results in patients. VAC dressing produces more split skin grafts before discharge and less rate of amputation.

\begin{tabular}{|c|c|c|c|}
\hline $\begin{array}{l}\text { Culture Sterility in } \\
\text { Cases }\end{array}$ & Pre-VAC & Post-VAC & Total \\
\hline Sterile & $\begin{array}{c}5 \\
20.00 \%\end{array}$ & $\begin{array}{c}23 \\
92.00 \%\end{array}$ & $\begin{array}{c}28 \\
56.00 \%\end{array}$ \\
\hline Non-sterile & $\begin{array}{c}20 \\
80.00 \%\end{array}$ & $\begin{array}{c}2 \\
8.00 \%\end{array}$ & $\begin{array}{c}22 \\
44.00 \%\end{array}$ \\
\hline Total & 25 & 25 & 50 \\
\hline \multicolumn{4}{|c|}{$\begin{array}{l}\text { Table 7: Analysis of Culture Sterility } \\
\text { in Pre-VAC and Post-VAC State }\end{array}$} \\
\hline
\end{tabular}

Chi square: 26.299; $\mathrm{p}<0.001$
Chi square test shows significant statistical association as $\mathrm{p}$ value is $<0.001$. Patients with sterile pre-VAC culture are not turning unsterile after VAC. But $90 \%$ unsterile turns sterile after VAC.

\section{DISCUSSION}

The use of VAC is increasing, especially in reconstruction of complex wound defects. The VAC acts as a new step in the 'reconstruction ladder.' The VAC enhances the tissue granulation, which makes it possible to use less complex reconstruction options, e.g. converting the wounds acceptable for the skin grafting which otherwise would have required flap coverage. The use of VAC in the treatment of a variety of wound types include extensive degloving injuries.8,9 infected sternotomy wounds. ${ }^{10,11}$ and various soft tissue injuries prior to surgical closure. ${ }^{12}$ grafting or reconstructive surgery. ${ }^{13}$ Use of the suction tubing creates a continuous negative-pressure dressing. This device has been associated with accelerated development of granulation tissue.14,15 earlier reepithelialization of wounds and faster healing of burn wounds and has been used to manage very complex wounds successfully.

Here, we studied the advantages of VAC over conventional dressing in the management of chronic non-healing ulcers. Apart from decreasing hospital stay VAC dressing improves pus culture sterility, improves outcome by decreasing the number of amputations and increasing the number of patients undergoing skin grafting. It is further shown in our study to have better results in patients with normal Doppler findings.

\section{CONCLUSION}

In conclusion this study shows a positive effect of vacuumassisted closure therapy on wound healing, expressed as a significant reduction in hospital stay, decreased amputations, increasing the number of patients undergoing skin grafting and improving culture sterility. From our observations, we support using negative-pressure dressings over chronic ulcer sites and believe that to better quantify outcome measures, further study of this device in a prospective, randomized fashion is warranted.

\section{REFERENCES}

1. Fleischmann W, Strecker W, Bombelli M, et al. Vacuum sealing as treatment of soft tissue damage in open fractures. Unfallchirurg 1993;96(9):488-92.

2. Argenta LC, Morykwas MJ. Vacuum-assisted closure; a new method for wound control and treatment: clinical experience. Ann Plast Surg 1997;38(6):563-76.

3. De Franzo AJ, Argenta LC, Marks MW, et al. The use of vacuum assisted closure therapy for the treatment of lower extremity wounds with exposed bone. Plast Reconstr Surg 2001;108(5):1184-91.

4. Wu SH, Zecha PJ, Feitz R, et al. Vacuum therapy as an intermediate phase in wound closure: a clinical experience. Eur J Plast Surg 2003;23:174-6.

5. Heller L, Levin SL, Butler CE. Management of abdominal wound dehiscence using vacuum assisted closure in patients with compromised healing. Am J Surg 2006;191(2):165-72.

6. Van Der Velde M, Hudson DA. Vader (vacuum assisted dermal recruitment): a new method of wound closure. Ann Plast Surg 2005;55(6):660-4. 
7. Mendonca DA, Cosker T, Makmana NK. Vacuum-assisted closure to aid wound healing in foot and ankle surgery. Foot Ankle Intl 2005;26(9):761-6.

8. Morykwas MJ, Argenta LC, Shelton-Brown EI, et al. Vacuum-assisted closure: a new method for wound control and treatment: animal studies and basic foundation. Ann Plast Surg 1997;38(6):553-62.

9. Genecov DG, Schneider AM, Morykwas MJ, et al. A controlled subatmospheric pressure dressing increases the rate of skin graft donor site reepithelialization. Ann Plast Surg 1998;40(3):219-25.

10. Meara JG, Guo L, Smith JD, et al. Vacuum-assisted closure in the treatment of degloving injuries. Ann Plast Surg 1999;42(6):589-94.

11. DeFranzo AJ, Marks MW, Argenta LC, et al. Vacuumassisted closure for the treatment of degloving injuries. Plast Reconstr Surg 1999;104(7):2145-8.
12. Obdeijn MC, De Lange MY, Lichtendahl DH, et al. Vacuumassisted closure in the treatment of poststernotomy mediastinitis. Ann Thorac Surg 1999;68(6):2358-60.

13. Tang AT, Ohri SK, Haw MP. Vacuum-assisted closure to treat deep sternal wound infection following cardiac surgery. J Wound Care 2000;9(5):229-30.

Bauer P, Schmidt G, Partecke BD. Possibilities of preliminary treatment of infected soft tissue defects by vacuum sealing and PVA foam. Handchir Mikrochir Plast Chir 1998;30(1):20-3.

14. Avery C, Pereira J, Moody A, et al. Clinical experience with the negative pressure wound dressing. Br J Oral Maxillofac Surg 2000;38(4):343-5. 